\title{
The Placement of Exanthema Characteristic for Adult Acne Among Women
}

\author{
Izabela Załęska*1 and Anna Kamm²,3 \\ ${ }^{1}$ The Section of Professional Cosmetology, University of Physical Education in Krakow, Poland \\ ${ }^{2}$ The Department of Medical Chemistry of Medical University of Gdańsk, Poland \\ ${ }^{3}$ The Department of Physiotherapy and Health Sciences of Management College in Gdańsk, Poland
}

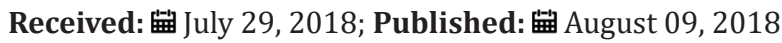

*Corresponding author: Izabela Załęska, 052The Section of Professional Cosmetology, The Faculty of Motor Rehabilitation, University of Physical Education in Krakow, Jana Pawla 78 Road, 31-571 Krakow, Poland

\section{Mini Review}

Adult women, living in a contemporary world are exposed to a series of illnesses. A faster and more demanding professional lifestyle creates more stressful situations. The productive age, besides general good health condition also requires the right appearance. The skin as an organ, that is the most visible reflection of our inner condition and each physiological abnormality of organism can show itself in skin changes. That is exactly what happens in case of acne vulgaris among adult women. Everyday exposure to stress also seems to be one of the potential factors worsening the condition of skin of patients with acne. The nervous tension may cause the activation of inflammatory conditions of skin and appearance of exanthema [1]. Patients suffering from the problem of acne display much higher mental pressure than those suffering from other chronic diseases such as diabetes or asthma. Approximately half suffer from low self-esteem, and in drastic cases, it may lead to depression or suicidal attempts [2]. Scientists who research large groups of probands agree with Loughlin, that the illness may appear also in maturity [3]. The most characteristic skin changes for acne vulgaris are first blackheads and whiteheads, more seldom papules and pustules.

Their placement in most of the cases covers the area of lower part of the face: a jaw, cheeks, a chin and a neck. The research in India proved greater frequency of the problem appearance among women. In $80 \%$ it covered cheeks, less acute effects were visible on a chin, a nose, a jaw and a forehead. The European research points out to a jaw as the most common placement of inflammatory exanthema in most cases those were basic exanthema such as: a blackhead, a papule or a few pimples [4]. Dreno, while conducting research on 374 patients, had disproved his own previous theory regarding the appearance of exanthema that accompany acne in the lower part of the face. The surprising fact was that in $90 \%$ of the researched, the placement of exanthema was the same as in their puberty. Due to such results, it was proposed to start treating adults by using standard treatments that were dedicated to teenagers [5]. Personal research conducted on a group of 60 women, which had the purpose of showing the influence of Ferulic acid substance and d'Arsonwal's currents on the number of exanthema among adult women suffering from acne, showed essential facts [6]. Besides confirming the decrease of both inflammatory and noninflammatory exanthema, the observation was also conducted that aimed at pointing out the placement of exanthema on probands' faces (Table 1).

Table 1: ${ }^{1} \mathrm{Chi}^{2}(4,81) ;{ }^{2} \mathrm{Chi}^{2}(0,01) ;{ }^{3} \mathrm{Chi}^{2}(0,10) ;{ }^{4} \mathrm{Chi}^{2}(0,34) ;{ }^{5} \mathrm{Chi}^{2}$ $(0,35) ;{ }^{6} \mathrm{Chi}^{2}(0,35) ;{ }^{7} \mathrm{Chi}^{2}(1,02)$.

\begin{tabular}{|c|c|c|c|c|}
\hline & $\begin{array}{c}\text { Ferulic acid } \\
\mathbf{( N = 3 0 )}\end{array}$ & $\begin{array}{c}\mathbf{D}^{`} A r s o n w a l \\
\mathbf{( N = 3 0 )}\end{array}$ & $\begin{array}{c}\text { In total } \\
\mathbf{( N = 6 0 )}\end{array}$ & Value p \\
\hline forehead & $10(33,3 \%)$ & $3(10,0 \%)$ & $13(21,7 \%)$ & 10,0283 \\
\hline cheeks & $22(73,3 \%)$ & $22(73,3 \%)$ & $44(73,3 \%)$ & 21,00 \\
\hline jaw & $7(23,3 \%)$ & $6(20,0 \%)$ & $13(21,7 \%)$ & 30,7540 \\
\hline chin & $9(30,0 \%)$ & $7(23,3 \%)$ & $16(26,7 \%)$ & 40,5593 \\
\hline chest & $2(6,7 \%)$ & $1(3,3 \%)$ & $3(5,0 \%)$ & 50,5536 \\
\hline back & $2(6,7 \%)$ & $1(3,3 \%)$ & $3(5,0 \%)$ & 60,5536 \\
\hline neck & $0(0,0 \%)$ & $1(3,3 \%)$ & $1(1,7 \%)$ & 70,3132 \\
\hline
\end{tabular}

No significant statistical changes regarding the placement of exanthema on face parts between two groups of probands were noticed. However, the cheek is the most commonly afflicted part of the face in both groups that treated with Ferulic acid - 22 $(73,3 \%)$ and d'Arsonwal's currents - 22 (73,3\%). When following Dreno and other scientists' research, in most cases the lower part of face is dominant in case of exanthema placement. Only single Dreno study, shows a different state, when comparing the face distribution covered by acne to features characteristic for teenagers. Also, personal observations prove that the cheek is the part of skin covered with exanthema the most. Then, the suggestion to start adult treatment from standard treatments applied among teenagers does not seem entirely right. As Dreno himself evaluates, 
adult skin shows higher tendency towards irritations and slower reaction to treatments. Therefore, it requires correct adjustment of therapy to the patient's age [4].

\section{References}

1. Dumont Wallon G, Dréno B (2008) Acné de la femme de plus de 25 ans spécifique par sa clinique et les facteurs favorisants. Étude rétrospective de 79 femmes. Press Medicale 37(4): 585-591.

2. Zeichner JA (2013) Evaluating and treating tha adult female patient with acne. J Drugs Dermatol 12(12): 1416-1427.

3. Loughlin M (1964) Acne in the Adult Female. Australas J Dermatol 7(4): 218-222.

ISSN: 2574-1241

DOI: _10.26717/BJSTR.2018.07.001552

Izabela Załęska. Biomed J Sci \& Tech Res

(c) (i) This work is licensed under Creative Submission Link: https://biomedres.us/submit-manuscript.php
4. Dréno B, Layton A, Zouboulis CC, López Estebaranz JL, Zalewska Janowska A, et al. (2013) Adult female acne: A new paradigm. J Eur Acad Dermatology Venereol 27(9): 1063-1070.

5. Dreno B, Thiboutot D, Layton AM, Berson D, Perez M, et al. (2015) Largescale international study enhances understanding of an emerging acne population: adult females on behalf of the Global Alliance to Improve Outcomes in Acne. JEADV 29: 1096-1106.

6. Kamm A, Załęska I (2018) The Effect of Ferulic Acid and D`Arsonwal's High Frequency Currents ctivity over the Number of Exanthema among Adult Women. Med - Clin Res \& Rev 2(4): 1-7.

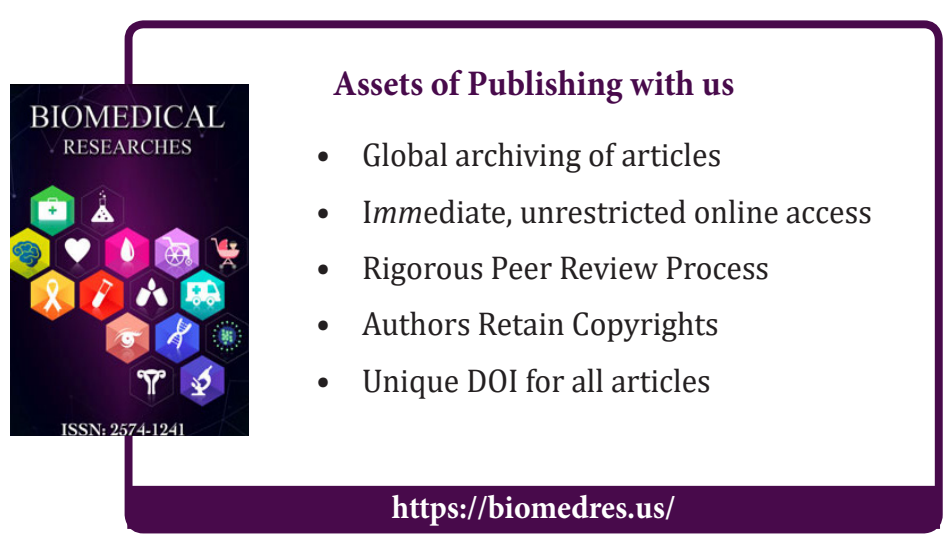

